\title{
Transforming Research Results in Food Safety to Community Actions: A Call for Action to Advance Food Safety in Ethiopia
}

\author{
Wondwossen Birke, Firdu Zawide* \\ Department of Environmental Health and Technology, Faculty of Public Health, Jimma University, Ethiopia
}

Copyright $\mathrm{C} 2019$ by authors, all rights reserved. Authors agree that this article remains permanently open access under the terms of the Creative Commons Attribution License 4.0 International License

\begin{abstract}
On April 7, 2015 when WHO celebrated the World Health Day, the slogan was "From Farm to Plate, Make Food Safe". On this day the Jimma University launched the campaign to create public awareness on food safety by organizing a one-day workshop for over 100 residents representing consumers, food service providers, government regulators, health extension workers, teachers and community leaders. The Jimma University's, Environmental Health and Technology Department has been conducting research on food safety since 2009 and the event of the 2015 World Health Day created an opportunity to present the research findings to the community members in order to reach a consensus on how to transform research results to concrete action in a participatory approach. Our research on food safety constituted community based cross-sectional survey of randomly selected 825 households and 718 food establishments in 13 Sub-cities of Jimma town, Southwestern Ethiopia. Evaluation of food safety knowledge, attitude, and practice of households and food service establishments was conducted using pretested and structured questionnaires for the interview. The proper enforcement of the current food safety laws and regulations by local government health inspectors and health extension workers and the procedure applied was evaluated on the basis of the critical role inspection plays in providing the different stakeholders the education, information and motivation necessary to make informed decisions on food safety. Different levels of compliance of food establishments to current food laws and regulations were assessed including reasons for noncompliance. Intervention measures to remove barriers to compliance were identified and the necessary actions to be taken to improve hygiene practices of food handlers and the sanitary condition of food premises to prevent the outbreak of foodborne diseases in the community were presented in the workshop. The outcome of the workshop was awareness creation and preparation of action plan to improve food safety of households and catering
\end{abstract}

establishments in Jimma town. The study provides evidence based food hygiene and safety behaviors of households and micro and small food establishments that have significant health and economic impact. The study recommends the strengthening of the food inspection and laboratory services; development of laboratory based foodborne disease surveillance system, extension of the local, regional and national information, education and communication services and ensuring the safety of food imports and exports. It concludes by suggesting the way forward to advance food safety in Ethiopia with specific recommendation.

Keywords Food Hygiene, Regulatory Compliance, Risk Assessment, Food Inspection, Consumers Education and Communication

\section{Introduction}

The rise in foodborne diseases and global food recalls are good indicators of emerging food safety problems which require unified approach by all countries to protect human health and promote international trade. The issues may vary from country to country but interventions should start at local level. The overall aim of this research was to reduce the burden of foodborne diseases and enhance the health and economic benefits of safe food production for domestic consumption and export by improving sanitation and controlling the environmental hazards (physical, chemical, biological) in places where food is produced, processed, marketed, prepared and consumed. In order to achieve this aim, there were six objectives: 1. create awareness and promote advocacy on the rising health and economic threats of food contamination and adulteration in the country resulting in the increase of foodborne diseases; 2. provide evidence based situation analysis of the hygiene 
and sanitary condition of households and small food enterprises including street markets to improve decision making capabilities of policy makers; 3 . assess the effectiveness of the current food inspection system and the enforcement of relevant food safety regulations on the basis of compliance; 4. evaluate the knowledge, attitude and practice of food handlers in households and small food enterprises to improve understanding of food contamination and spoilage in order to practice good hygiene as preventive action; 5 . identify and examine the barriers for noncompliance and recommend appropriate measures for the enforcement of regulations; 6 . provide the basis for developing national food safety policy, strategy and action plan based on holistic approach and risk assessment applying the principle of critical control points and critical limits including the way forward and recommendations.

This paper will present empirical evidence on the background problem of food safety. It concentrates on the epidemiology of foodborne diseases, bacteriological contamination of food, and food safety risk assessment "farm to table". Research methodology, results, discussion and conclusion, the way forward, and recommendations are given in Part 2-7, respectively.

\section{Background}

\subsection{Epidemiology of Foodborne Diseases}

Food insecurity and malnutrition in all its forms dominate government agendas and the news media in most of the developing countries including Ethiopia. Ethiopia is not a land of famine but potentially a rich country where transforming just one of its fertile regions can feed the entire nation if food safety and security are given more attention. It is ironic that wheat tops the list of imported food stuff in Ethiopia while there are many places in the country which can be developed for grain production [1]. In contrast food safety is one of the essential conditions for public health development which is not well understood and usually overlooked by the public health authorities. This is because the majority cases of foodborne illnesses are not reported since the initial symptoms of most of the diseases are not severe to require medical attention. Although there are more than 250 foodborne diseases caused by pathogenic organisms that enter our food chain, the data we get from different sources on the morbidity and mortality of the diseases arising from these pathogens is the tip of the iceberg [2]. In 2015 WHO released the full results of the research on a broader analysis of the global burden of foodborne diseases undertaken by WHO's Foodborne Diseases Burden Epidemiology Reference Group (FERG). The results show that there were an estimated 600 million cases of 22 different foodborne enteric diseases and 420,000 deaths including 125,000 children under the age of
5 years. Diarrheal diseases are responsible for more than half of foodborne diseases causing 550 million cases and 230,000 deaths every year. The African region recorded the highest disease burden for enteric foodborne disease, followed by South East Asia. The enteric disease agents responsible for most deaths were Salmonella Typhi, enteropathogenic E.coli and norovirus [3].

Epidemiological data on the burden of foodborne diseases are meager in Ethiopia due to lack of laboratory based surveillance system. Most foodborne illnesses are not reported unless they occur in epidemic proportion. Many of those reported are never traced to a particular food or the sources and the causative agents identified. Ethiopia has been implementing the Integrated Disease Surveillance and Response (IDSR) strategy since the year 2000. According to data reported on priority diseases and events on a weekly basis by the Ethiopian Public Health Institute, diarrhea remains the third leading cause of under-five mortality attributed to poor water, food hygiene and sanitation. Outbreaks of typhoid fever, acute watery diarrhea and dysentery have been also reported from different Regions of Ethiopia in recent years [4]. In April 2017 Ethiopia declared acute watery diarrhea (AWD) in the Southern border with Somalia resulting in 19 deaths mostly children and more than 700 illnesses that required treatment [5]. Earlier in 2007 a suspected outbreak of cholera epidemic which was reported as acute watery diarrhea by the government resulted in 60,000 cases and 684 deaths in less than a year [6]. Annual Report of Epidemic Diseases from a national outpatient health facilities showed that dysentery and typhoid fever cases were 140,867 and 323,008 , respectively. Whereas the number of annual national inpatient dysentery and typhoid fever cases/deaths were 1,264 (16 deaths) and 3,545 (12 deaths), respectively. The extent of the problem is far greater than what is reported since the majority of cases are not properly diagnosed and not all people who are sick with foodborne diseases visit health facilities.

\subsection{Bacteriological Contamination of Food}

Available data show that foodborne bacterial diseases are caused in Ethiopia mainly by Salmonella spp., Campylobacter, Listeria, E.coli and Mycobacterium [7]. In Ethiopia one confirmed case of cholera caused by ingesting food or water contaminated with the bacterium Vibrio cholerae is enough to declare an outbreak [8]. Foods of animal origin and green vegetables that are eaten raw are considered to be the major sources of foodborne Salmonellosis. Several epidemiological research and case control studies have indicated that the majority of reported foodborne outbreaks originate in food service establishments confirming that eating meals outside the home is a risk factor for foodborne illness [9]. The studies further indicate that most outbreaks associated with food service establishments can be attributed to food workers' 
improper and unhygienic food handling and preparation practices. This means failure to apply appropriate hygiene and sanitation practices [10]. The deplorable sanitary condition of the premises where food is produced, prepared and marketed have been identified as a major source of food contamination according to several studies on hygiene standards of food catering establishments in large and small towns of Ethiopia.

There are a few laboratory studies that confirm the sources of bacterial contamination of food and the health risk of food workers. In one study the overall prevalence of Salmonella isolated from minced meat beef, mutton and pork from retail supermarkets in Addis Ababa was 14.7\%. Salmonella was detected in $14.45 \%$ minced beef, $14.1 \%$ mutton, and $16.4 \%$ pork samples subjected to isolation and identification [11]. Prevalence of Salmonella in milk from lactating cows and stool samples from humans working in the dairy farm were $10.7 \%$ of cow, and $13.6 \%$ of human [12]. The prevalence of Salmonella recorded in eggs from Kombolcha poultry multiplication and breeding farm and market were $11.5 \%$, from which $6.3 \%$ were found from egg shell and $6.8 \%$ from egg content [13]. The prevalence of Salmonella in apparently healthy slaughtered cattle (Liver, mesenteric lymph nodes, intestinal content and carcass swab) at Bahir Dar abattoir, at animal level were 7\% [14].

Campilobacter is the leading cause of bacterial foodborne disease worldwide resulting mainly from the contamination of poultry or other meats, raw milk, other milk products and surface water [15]. According to studies of abattoirs in Addis Ababa and Debre Zeit, the overall prevalence of Campilobacter spp isolated from meat samples were $9.3 \%$. The highest prevalence recorded was $21.7 \%$ in chicken meat, followed by sheep meat $10.5 \%$, pork meat $8.5 \%$, goat meat $7.6 \%$, and beef $6.2 \%$. Among the isolates $78 \%$ were identified to be C.jejuni, $18 \%$ were C.coli, and $4 \%$ were C.lari [16]. Similar study in Jimma Zone on the overall prevalence of thermos tolerant Campylobacter spp in various food animals (cattle, poultry, pigs and sheep) showed $39.6 \%$. The highest isolation rate were recorded among chicken $68.1 \%$, followed by pigs $50 \%$, sheep $38, \%$, and cattle $12.75 \%$. Among the thermosphilic Campylobacter isolated $70.35 \%$ were identified to be C.jejuni, $26.6 \%$ were C.coli, and $3.1 \%$ were C.clari. Thermophilic Campylobacters are very frequent among various food animals in Ethiopia suggesting possible risks of infection to people through the consumption of contaminated animal products or through contact with infected animals [17].

In Ethiopia the wide spread habit of raw meat consumption is the common cause of the parasitic disease, tapeworm Taneia and other potential foodborne illnesses as raw meat is sold in retail butcheries that have no refrigerating or cold room facilities. Minced meat known as "Kitfo" is a traditional meal and is eaten raw or slightly cooked in households and restaurants and is likely to contribute to foodborne diseases due to poor meat hygiene.
Recent reports also indicate that the overall prevalence of Listeria in retail meat and dairy products in Addis Ababa and its surrounding towns were $27.5 \%$. From this the prevalence rate of L.monocytogen reported was 5.4\% [18]. The report on the overall prevalence of L.monocytogen and other Listeria species from foods of animal origin isolated from cake, raw meat, ice cream, minced beef, fish, unpasteurized milk and pizza in Gondar were 6.25\% [19]. The presence of a small number of pathogens in carcass meat and edible offal may lead to heavy contamination of minced beef when it is cut into pieces, as more organisms are added to the surface of exposed tissue. Outbreaks of infections somehow related with poor hygiene and consumption of contaminated food have been reported in Ethiopia and some of them were caused by Salmonella and Shigella [20]. Although the studies are limited sheep and goat can be potential source of E.coli 0157:H7 for human infection in Ethiopia as confirmed by samples taken from fecal and skin sources. As animals and people sleep in the same house in rural areas there is frequent contact with the skin and excreta that transmit infection.

Various studies carried out in different parts of Ethiopia also indicate that the environmental conditions under which food is produced, stored, prepared and consumed at home and in catering establishments pose a significant public health risk. In one study bacteriological examination of food utensils from 12 students catering services located in 7 campuses of the Addis Ababa University, swab samples taken from the eating plates and drinking bowls showed the presence of E.coli and S.aures as well as a total faecal coliforms, Aerobic mesophilic bacteria $(>100$ colonies/utensil). S.aures were isolated from $2.8 \%$ of swabbed utensils and E.coli were not detected from all the swabbed utensils. Acid and gas formation was seen in $19.4 \%$ of the examined utensils confirming the presence of total and faecal coliform [21]. These results were somewhat better than what was recorded from Mekele town in which E.coli and S.aures were isolated from $18.2 \%$ and $27.3 \%$ of the swabbed utensils, respectively [22]. And it was comparable with the study conducted in South Ethiopia [23]. These results indicate the sanitary deficiency of the utensils, equipment and food contact surfaces including the washing facility such as lack of adequate and safe running water and detergents. However the isolation of S.aures shows the existence of poor hygiene of the food handlers due to contamination through air particles while coughing or sneezing during the course of work or due to the presence of food handlers with certain infectious disease.

In another study a survey of 127 food handlers working in the University of Gondar Northwest Ethiopia students' cafeteria, Staphylococcus aures, Klebisella, E.coli, Seratia and Citobacter were isolated from $16.5 \%, 5.6 \%, 3.1 \%$, $1.58 \%$, and $0.8 \%$ of the finger nails content of food handlers [24]. Similar study in Jimma town of 105 stool samples taken from food handlers working in one food 
factory, 6 were found to be infected with Shigella, which caused an outbreak of foodborne illness [25]. In the same study examination of the quality of water in Jimma town revealed high E.coli count ( 9 per $100 \mathrm{ml}$ ). In Bahir Dar town S.typhi was isolated from 6 out of 25 food handlers (24\%) with history of diarrhea [26]. Similarly prevalence of intestinal parasitic illnesses and obvious cases of active skin and upper respiratory infections were recorded among food handlers.

Of equal concern related to the control of foodborne diseases in Ethiopia is the increase in antibiotics resistance (AMR) due to extensive use of antibiotics in human health and agriculture. The inappropriate use of antibiotics among health providers and the food animal industry, combined with limited understanding of AMR, has worsened Ethiopia's AMR. Foodborne infectious diseases of bacterial origin are no longer treated effectively with commonly prescribed antibiotics due to development of drug resistant micro-organisms. Although large scale studies on antimicrobial resistance in Ethiopia have not been yet conducted, the available reports indicate a trend towards increasing resistance rates among pathogens such as Escherichia coli, Shigella spp, Salmonella spp and Staphylococcus aures to commonly prescribed antibiotics, including ampicillin, amoxicillin, penicillin, tetracycline and trimethoprim/sulfamethhoxazole [27].

In 2017 the Ethiopian Anti-Microbial Resistance Surveillance Coordinating Centre was established by the Ethiopian Public Health Institute (EPH) under the Federal Ministry of Health (FMOH) with the support of the Ethiopian Food, Medicine and Health Care Administration and Control Authority (EFMHACA) and other partners. The AMR surveillance network will provide clinicians and public health officers with the information they need to identify AMR and use the best medicine to help make people well [28]. According to the operation plan AMRS sentinel surveillance sites submit data and isolates to the national reference laboratory at the Ethiopian Public Health Institute and there will be an infrastructure for data capture and information sharing with sentinel sites that will be established in phases nationwide with support of international partners including the United States CDC. The possibility of integrating foodborne disease surveillance programme with the AMR surveillance network should be explored in order to save cost in the future.

It is also recognized that aflatoxin is a public health and economic threat in several African countries due to the contamination of crops such as maize, groundnuts and other cereals by the toxin during harvesting and storage in the farm. Exposure to aflatoxin due to consumption of contaminated cereals results in human disease. Aflatoxin $\mathrm{B} 1$ is the most frequently occurring subtype and is found in most feeds and foods and highly carcinogenic causing liver cancer in humans. According to the World Bank, the exaggerated aflatoxin tolerance level of Maximum
Allowable Levels of four parts per million cost African countries $\$ 670$ million in annual export losses of cereals, dried fruits, and nuts [29]. In Ethiopia a study on Knowledge, Attitude and Practice of Farmers towards aflatoxin in cereal crops carried out in Wolaita Zone, Southern Ethiopia in 2017, showed that the majority of the farmers were aware of aflatoxin and its health effect but they were not aware of toxins other than aflatoxin. It was reported that some individuals who drink the local alcoholic drink "areke (Katicala)" brewed from spoiled (infested) maize were exposed to psychosis and liver disease in the past [30]. Factors influencing the growth of aflatoxin on crops in the field include drought, high temperature, high humidity, insect infestation and inadequate crop storage practices. The absence of monitoring the enforcement of the regulatory limits and lack of inspection contribute to the favorable growth of the fungus. Some of the practical methods of reducing the health effects of aflatoxin include proper drying and storage of crops following harvesting, control of insect infestation, removing spoiled cereals and enforcement of regulations that limit the maximum tolerance level in foods.

Another food safety concern in Ethiopia is the practice of adulterating food for financial benefits by unscrupulous merchants and petty traders who want to make quick profit. The deliberate mixing of milk with water, flour with gypsum, butter with banana, edible oil with poisonous plant derivative, pepper with clay have been some of the reported cases in recent years. Fraudulent practices will still continue to be on the increase especially in rural and semi urban areas where there is no formal food inspection to insure that food laws and regulations are enforced. This calls for urgent action to combat fraud in the country by exposing food adulterers to the public and punishing them severely.

\subsection{Food Safety Risk Assessment "Farm to Table"}

The food supply chain from "Farm to Table" is long and complex stretching from primary production of crops, livestock, poultry, fish, fruits and vegetables in the field to processed, canned, packaged, frozen and dried products, manufactured by industries in large quantity and distributed to supermarkets, whole sale and retail stores and open markets. The chain continues until the food is brought to individual homes, restaurants and other food serving institutions and other places for final preparation and consumption. If at any one time of these steps food is exposed to potentially hazardous agents, pathogens, bacteria, viruses, parasites, molds, insects, rodents, toxins, poisonous chemicals and other contaminants there is a risk of adverse health effect. Therefore keeping food safe is a shared responsibility of the farmers, primary producers, processors, distributors, retailers, food vendors, service providers, government regulators and individual 
consumers [31]. Creating awareness among the stakeholders about the delicacy of food and the risk factors that expose food to hazardous substances in the supply chain in order to reduce the burden of foodborne illnesses remains to be a huge challenge.

In the farm food can be contaminated during harvesting and storage by hazardous chemicals and molds (aflatoxin), pesticides, fertilizers, herbicides which also impact the post-harvest food loss. Other risk factors associated with farm activities include growing of vegetables in polluted irrigation water, slaughtering of animals for beef without examination, milking cows with hands in unsanitary condition, raising poultry in the open and contaminated ground, catching fish from polluted inland fresh water or aquaculture, and storing grains in containers that perpetuate the growth of molds. In Ethiopia the informal sector plays a very large role in the urban and semi urban food retail markets. Rural farmers, petty traders and food vendors carry their produce from distance places to the open markets to sell their products to urban and peri-urban dwellers. Along the way there is a risk of food contamination by chemical and biological hazards.

Most of the informal open markets are without a permanent built up structure but may have temporary shades occupying space on the pavement side or municipal open area or may be mobile moving from place to place carrying their wares on push carts or baskets on their heads [32]. Raw and ready to eat foods prepared and sold to the public in the open markets are perceived as a major public health threat because of the poor environmental condition to which they are exposed, and the unhygienic status of the vendors and traders. Where stalls and kiosks are not provided, food is exposed to the sun, dust, wind, smoke, flies and dirty surfaces with a risk of contamination by microorganisms and other vectors. Facilities such as running water, toilets, drainage, garbage disposal and clean storage areas are nonexistent in most of the informal markets. It is also recognized that mishandling and disregard of hygiene measures on the part of the street vendors may enable pathogenic bacteria to come into contact with and in some cases survive and multiply in sufficient numbers to cause illnesses to the consumers [33]. If food bought from the informal markets is not properly cooked or washed and handled safely to ensure the destruction of pathogenic microorganisms it would be the cause of foodborne epidemics.

In Ethiopia most of the agricultural products are used to meet household consumption needs. Smallholder farmers consume food produced by themselves and take their surpluses to the nearest market for sell in order to purchase processed food such as sugar, flour, cooking oil, salt, spices, rice and pasta. In rural households food is often prepared and consumed immediately with or without left over for storage thus reducing the risk of cross contamination and abuse of temperature. Rural dwellers also consume more cooked cereals and raw fruits and vegetables. On the other hand urban households purchase most of their food from open markets, grocery stores, and supermarkets. Data from 2009 household consumption survey carried out in Jimma town show that "injera", the staple food prepared from the grain (Teff) flour is consumed by $99 \%$ of the respondents, followed by cereals $48 \%$, vegetables $28 \%$, rice $33 \%$, meat $33 \%$, fish $31 \%$ and pasta $31 \%$. In the same survey it was found that $86 \%$ of the food was purchased from open markets, $2 \%$ from grocery stores and $6 \%$ from private vegetable garden [34]. Although 'injera' made from (teff) flour is the preferred food, maize and wheat are also consumed by a large number of the population. There is considerable evidence that the urban dwellers consume more meat, dairy products including cheese and butter, chicken, eggs, fish, pulses, fruits and vegetables than their rural counterparts. Studies also show that cereal consumption is going down in urban households while consumption of animal and processed food is going up due to large difference in income levels [35].

Ethiopia is a fast growing economy facing rural-urban migration problem. Due to this transition, food habits of people is changing with more people in urban areas eating outside the home and giving preference to ready-to-eat food sold in the open market and small restaurants at a low price. Current food safety and hygiene practices among households, restaurants and street food vendors generally demonstrate gross health risks to consumers. This does not mean that the risk for foodborne diseases will be eliminated but there is room for improvement to reduce the risks if basic hygiene and sanitary practices are implemented in all places where food is produced, processed, prepared and consumed. This study provides a bench mark for a nationwide alert of the prevailing health risks paused by food exposed to various environmental hazards in the place of production, processing, marketing, preparation and consumption, and calls for action to improve the situation in a concerted manner. Similar researches carried out in Addis Ababa, Bahir Dar, Gondar, Mekelle, Agaro, Awassa towns have concluded that the current sanitary condition of catering establishments in large and small towns of the country pose significant threat to public health and should be given active and serious consideration to reduce the burden of foodborne diseases [21, 36-41].

\section{Materials and Methods}

This investigation was carried out in three stages to address the current food safety issues in Ethiopia by choosing a study area Jimma town, $356 \mathrm{Km}$ Southwest of Addis Ababa. The first study examined the knowledge, attitude and practices of food handling, preparation and consumption of households, and the sanitary condition of food catering establishments including hygiene behavior of food workers.

The second phase of the study evaluated the compliance 
of the food establishments to existing food safety regulations enforced by the local municipal and health authorities, and the effectiveness of the present food inspection system by environmental health officers and health extension workers. In this process the major constraints that limit the performance of the health inspectors including the compliance problem of food establishments to existing food safety laws and regulations were identified. This was followed by developing intervention strategy by preparing training manual on food safety in the local language for distribution to stakeholders in the community.

The third phase was focused on creating awareness by launching a food safety campaign on April 7, 2015 while commemorating the World Health Day by organizing a training workshop for members of the community including health inspectors, health extension workers, government health officials, food business managers, school teachers, street vendors, food traders and handlers. Workshop participants were briefed about the findings of the previous research which was the basis for the workshop, and were given lectures on food safety. At the end of the workshop participants held group discussion and assessed the risks of exposure to foodborne diseases. This was followed by drafting a strategy and action plan to reduce the burden of foodborne diseases by improving food safety in their community. The implementation of the action plan is currently being monitored by the health inspectors and health extension workers.

\section{Methods and Procedures}

Information on food safety knowledge, attitude and practice of selected households and food service providers in the community was gathered by completing pre-tested questioners and conducting face to face interview. The survey instruments were first prepared in English and then translated to the local language (Oromia) to ensure the validity and consistency of the content. Environmental health professionals working in Jimma town who speak the local language (Oromia) and familiar with their local geography and tradition were recruited and trained for data collection. They visited the selected households and food establishments based on whether the respondents were willing to participate and allow to be included in the study. If the respondents did not wish to participate in the study, the data collectors selected the next home or food establishment on the list. The interview protocol and the questionnaires were piloted to ensure questioning was targeted and clear to understand. Respondents were assured anonymity within the research report. The collected data were edited and entered into a computer using SPSS Software 20.0 version (SPSS, Inc., Chicago, III, US). Descriptive and inferential methods were applied for data analysis.

Ethical clearance was obtained from the Ethical
Committee of the Faculty of Public Health, Jimma University. Then the concerned government officials in the Sub-cities were communicated through formal letters from Publication and Research Office of Jimma University. Informed verbal consent was obtained from the households and food establishments for the interviews. The interview was conducted privately and the confidentiality of the information received was ensured.

The outcome of the survey was evaluated and a summary of major findings was compiled on the basis of which food safety fact sheets and training manuals were prepared in English and then translated into the local language (Oromia) to create awareness and address the major risk factors identified in the community. The manuals were prepared based on publications and reference documents collected from the Food and Agriculture Organization of the United Nations (FAO); Food Code U.S Public Health Service (FDA) 2013, and the WHO websites.

This was followed by organizing a training workshop on the World Health Day, April 7, 2015, the theme of which was "Food Safety". Senior food safety instructors from the Department of Environmental Health and Technology of Jimma University gave lectures on selected food safety and hygiene issues. The presentation stimulated discussion on participatory problem solving approach that resulted in developing action plan and implementation strategies to improve food safety in the community. The outcome of the workshop was published and distributed to participants and all other stakeholders at a later date. The implementation of the recommendations is to be monitored by health inspectors and health extension workers.

\section{Results}

\subsection{Food Safety of Households}

\subsubsection{Study Population Socio-demographic Profile}

Out of a total of 840 households registered to participate in the study only 825 randomly selected households were involved in the survey which gave a response rate of $98.2 \%$. Among the total respondents, $42.4 \%$ were males and $57.6 \%$ females. Regarding age of respondents, $34.9 \%$ were in the age category of $18-27 ; 29 \%$ in the category of $28-37$; and $36.1 \%$ were in category 38 and more years, with mean age of 34.2 years. As far as their education is concerned, the most numerous group $33.1 \%$ were graduates of secondary schools (9-12 grades). Those who completed grades $(9-10)$ were $19 \%$ and grades $(11-12) 14.1 \%$. Those above grade 12 who graduated from college/or university were $14.9 \%$. The non-formal education groups included the illiterates $17.2 \%$, and the semi literates who read and write $12.4 \%$. The primary level educated respondents who completed grade (1-4) were $6.9 \%$ and from (5-8) $15.5 \%$. 


\subsubsection{Food Safety Knowledge, Attitude and Practices of Households}

Overall the great majority $99.4 \%$ (820) of household respondents showed some knowledge about potential food contamination sources. When asked about the specific food contamination sources $99.1 \%$ indicated human waste, $99.4 \%$ contaminated water, $99.3 \%$ dirty utensils, $99 \%$ dust and 99.1\% foods from infected sources. About $97.4 \%$ of respondents mentioned that pests such as flies, cockroaches, and rodents also contaminate food, and $98.3 \%$ were aware of negligence of storage temperature as a risk factor for food spoilage. The possible contamination of food by unclean and unhealthy food handlers was recognized by $98.8 \%$ of the respondents. Around $98.5 \%$ (721) out of 825 respondents knew that microorganisms such as bacteria and viruses are responsible for the cause of foodborne diseases. However when the respondents were asked whether they have heard of some of the major microbial foodborne pathogens only $10.3 \%$ (74) were familiar with Salmonella, 11.4\% (82) have heard about Shigella, 23.3\% (168) were aware of Staphylococcus aures, and 22.7\% (164) knew about Clostridium botulism.

The attitude of the respondents in terms of adopting cleaning and sanitizing of food preparation equipment and utensils; separating storage of raw and cooked food; avoidance of handling food with abrasive and wounded hands; careful study of food ingredient labels and expiry dates; and use of separate kitchen utensils for raw and cooked foods although looked favorable, their application in the actual practice was limited. This implies that the respondents did not put into action what they believed was right. The food handlers did not practice what they preach.

Further examination showed that about 811 respondents $(98.3 \%)$ were in agreement that adopting adequate cleaning and sanitizing procedures for utensils and food preparation equipment contributes to reducing the risk of bacterial contamination of food. Virtually all respondents 820 $(99.4 \%)$ agreed that the use of protective clothes such as clean gowns and gloves play important role in preventing food contamination, and $816(98.9 \%)$ were in favor of providing proper food storage facilities to avoid spoilage of perishable food. Only $18(2.2 \%)$ of respondents disagreed that food handlers with abrasive or cut hands should touch unwrapped foods. With regard to the study of food labels to understand the ingredients and the expiry dates, about 812 $(98.4 \%)$ respondents were in agreement that this was important information to consumers for food safety protection although most consumers do not take their time to read the labels on the food. Surprisingly those who agreed on eating food past its expiry date even if it smelled as long as it tasted good, was 819 (99.3\%). Regarding the risk of avoiding cross contamination of raw food (meat, poultry, fish, vegetables) and cooked food by segregating the storage facility and use of different utensils and cutting boards, about 399 (48.3\%) disagreed while 423 (51.3\%) were in favor.
The personal hygiene survey of food handlers at household level showed that about 589 (71.4\%) of the respondents wash their hands after using the toilet with only $179(21.7 \%)$ using designated wash basins for hands. A mixed set of responses were evident when considering the practice of washing hands before and after handling unwrapped, raw and cooked foods. Accordingly 478 $(57.9 \%)$ and $526(63.8 \%)$ of the respondents wash their hands before and after handling unwrapped raw foods, respectively. Whereas $437(53.0 \%)$ of the respondents wash their hands before handling unwrapped cooked foods and $512(62.1 \%)$ after handling cooked foods. About 537 (65.1\%) respondents said they use separate kitchen utensils to prepare cooked and raw foods. Those who separated the storage facility and the preparation areas for raw food and cooked food were about 659 (79.9\%) and 657 (79.6\%), respectively. The survey also found that practices such as checking food labels and washing raw vegetables, and meat before cooking was minimal 267 (32.4\%) and 197 $(23.9 \%)$, respectively.

\subsection{Food Safety Practices and Hygiene Compliance of Food Establishments}

\subsubsection{Study Population}

A total of 740 food establishments were identified from the 13 sub-cities for the survey and all of them completed the survey format and returned on time with a response rate of $100 \%$. Out of the 740 establishments, interviews were held with managers/owners of 718 randomly selected food service providers. The base population included 143 hotels; 83 restaurants; 95 cafeterias; 74 clubs; 42 bars; 72 local drink bars (Tej bets); 69 butcheries; 9 dairy farms; 1 abattoir; 47 bread retail shops; 25 bakeries; 7 fish retail shops; 51 fruits and vegetables street vendors.

About $445(62 \%)$ of the respondents were females while the rest 273 (38\%) were males. Regarding age 198 (27.6\%) were from $20-30$ years; $305(42.4 \%) 31-40$ years; 136 $(18.9 \%) 41-50$ years, and $79(11.1 \%)$ above 51 . The minimum and maximum ages were 20 and 65 years, respectively, and the median age was 34 years. The educational status of owners/managers was categorized into 7 levels. Accordingly 29 (4\%) were illiterate; $60(8.4 \%)$ read and write; $68(9.5 \%)$ between grade $1-4 ; 58(8.1 \%)$ between grade 5-8; 157 (21.8\%) between grade 9-10; 249 (34.7\%) between grade 11-12 and 97 (13.5\%) had further education after completing grade 12 .

\subsubsection{Licensing and Ownership}

Part three section six of the Ethiopian Government Proclamation to provide for safety and quality of food refers to registration and licensing of food establishments. According to the Proclamation any person may not operate a food catering service without obtaining a certificate of competence from the appropriate organ [42].

Contrary to the Proclamation 661/2009 on Food Safety 
Control, it was found that out of the total 718 food service establishments involved in this study, about $578(80.5 \%)$ had licenses. However only 434 (60.4\%) had current valid licenses (renewed licenses) for operation. Some of the small food businesses in the informal sector did not require license by law. Nearly $686(95.5 \%)$ of the establishments were owned privately and $32(4.5 \%)$ belonged to organizations. The majority of the establishments $(85.7 \%)$ were managed by owners themselves, $8.2 \%$ managed by relatives of owners, and $6.1 \%$ managed by hired personnel. Almost all the establishments (99.5\%) were managed by those with $<5$ years experiences in the food service business.

\subsubsection{Food Safety Risk Factors}

The survey identified several risk factors for foodborne illnesses in the establishments investigated. These included lack of hygiene compliance of food workers, poor sanitary and structural condition of food preparation and serving places; inadequate kitchen facilities and equipment giving rise to risks of cross-contamination, ineffective temperature control of food storage including refrigeration and cooling practices; unsanitary use of cutting boards, inefficient sanitizing of utensils and food contact surfaces.

\subsubsection{Knowledge and Practice of Food Handlers}

Generally there was no statistically significant difference in the knowledge, attitude and practice of food safety between households and food serving establishments. The majority of food handlers have adequate knowledge regarding the main cause of food contamination and the causes of foodborne diseases but fail to implement basic sanitary measures to reduce the risk of contamination. This may be due to negligence to follow the right practice, inadequate supply of basic sanitary facilities, lack of management support for food safety, and shortage of time and money.

Around $80 \%$ of the food workers showed inadequate knowledge about what was legally required of them to do, particularly in relation to general food hygiene principles. A large percentage $(95.8 \%)$ of the respondents reported that they had not heard of hazard analysis and critical control (HACCP) in the past. About $96.8 \%$ of the establishments lacked trained staff in food safety. None of the food workers had a certificate in food catering or took training in accordance with the principles of HACCP or received in house training by their employees in food hygiene. Only $23(3.2 \%)$ of the establishments had trained staff in food safety and only 24 (3.3\%) of food workers had medical check-up from time to time not on regular basis.

The number of food handlers who wear protective clothing (gown, gloves, hair restraints, hairnets) during preparing and serving food was found to be only 319 (44.4\%). Skin lesions, eye and nose discharges were observed among some food handlers. No health education was given to food handlers on personal hygiene such as washing hands before and after preparing food, trimming and keeping their finger nails clean, not wearing hand ornaments, covering open cuts and wounds with waterproof bandages, covering mouth when sneezing and coughing, and reporting to health care provider or food service manager when having diarrhea or other communicable diseases. This has resulted in poor hygienic practice of food handlers and increased risk of food contamination by food workers which may result in the outbreak of foodborne diseases.

\subsubsection{Preventing Cross-contamination}

In a healthy catering establishment food contact surfaces such as food preparation tables, cooking equipment and utensils, should be cleaned and sanitized at a given frequency using running water. Raw fruits and vegetables should be thoroughly washed in water to remove soil and other contaminants; table clothes and napkins should be replaced each time after use by a customer; towels for drying utensils should be kept dry and not used for other purpose; cooked food should be kept separated from raw foods; raw and cooked foods should be kept in clean covered containers and stored in protected location; food with visible soil on the surface of hermetically sealed containers should be washed before opening the containers; containers of food ingredients should have clear labels for ease of identification; food stuffs should be stored in dry condition where it is not exposed to dust, moisture splash, vectors and rodents at least 6" above the floor. Food must not be stored in lockers toilet rooms, dining room, garbage storage room and garages. All ingredients and raw materials used for food preparation should be inspected for quality, freshness and compliance with national standard. These are some of the important hygiene practices expected from catering establishment to protect consumers from foodborne diseases [11].

In this study it was found that only in about 210 (29.2\%) of the food establishments utensils and equipment were kept in sanitized clean condition, and cooked food was separated from raw food in about $416(57.9 \%)$ to avoid cross-contamination. Only about $144(49.7 \%)$ of the establishments kept food contact surfaces clean and in sanitary condition. None of the establishments used color coded chopping boards and utensils to prevent cross contamination (e.g. red for raw meat, brown for vegetables, blue for raw fish, yellow for cooked meat, green for salads and fruit, and white for bakery and dairy products). In 467 $(65 \%)$ of the establishments stored food was not properly covered and protected from contamination. In nearly 179 $(50 \%)$ of the establishments, insects and rodents were seen harboring the food preparation, storage and serving areas.

\subsubsection{Temperature/Time Control}

Food may be received at specific temperature as required depending on the type of food. In this regard perishable raw and ready to eat food (meat, poultry, fish, eggs, vegetables, 
milk) should be kept in refrigerator or freezer within 2 hours. Storing food at temperature lower than $40^{\circ} \mathrm{F}\left(5^{\circ} \mathrm{C}\right)$ will retard the growth of pathogenic organisms and the more important spoilage organisms, but it does not prevent all changes. Proper air circulation and regular cleaning and sanitizing of chill spaces is mandatory. Temperature for refrigeration or freezing is determined by the kind of food, the condition it is in, and the desired time for keeping it under refrigeration. The bacteria that cause food spoilage do not multiply at freezing temperature but when thawing begins frozen food becomes vulnerable to bacteria and the associated toxins they may produce. Frozen food is thawed in cold running water or refrigerator or using microwave. The storage space in the refrigerator for perishable and nonperishable foods should be separate. Preparing food long before it is consumed would result in temperature abuse unless there is adequate refrigeration. Storing food at ambient temperature after it is prepared is a major factor for bacterial contamination and food poisoning. Several studies show that high microbial counts were associated with food when held at room temperature for 4 hours or longer [11].

In this study $283(29.4 \%)$ of the establishments had refrigerators and 560 (78\%) kept perishable foods at room temperature. Fruits, vegetables and other food items were also stored at room temperature in about $75.8 \%$ of the food premises. Moreover only $37 \%$ of the respondents knew the correct temperature for refrigeration and only $2(0.3 \%)$ used thermometer. None of the establishments had a walking in type of refrigerator or built in cold store.

Most food workers feel that they don't need thermometers to check the temperature of the food because they know from experience how long it takes to cook the food, and by tasting and looking at it they can tell from the appearance when the food is ready for serving. Taking the temperature of every meat cooked or kept in the refrigerator was considered to be time consuming. Therefore there was no procedure for temperature control in any of the catering establishments. For this reason factors impacting holding, cooling, and reheating practices were not evaluated during the survey.

\subsubsection{Sanitary Facilities}

Each food establishment registered under the formal sector is subject to inspection and shall have premises, facilities, and equipment according to the requirement of the licensing authority or local health department. Generally food service establishments should be located on suitable sites that are easily accessible, properly drained and free of smoke, domestic animals, rodents and other vectors. There should be no garbage or other waste disposal or nuisance close to the site. All public health safety requirements should be considered in selecting the site or when giving approval for licensing. The building should meet the required structural safety standard to safeguard the wellbeing of the inhabitants and consumers and ensure the provision of the basic sanitary facilities such as running water, adequate liquid and solid waste disposal. The kitchen and dining rooms should be of adequate size and properly lighted and ventilated free of smoke, dust and cracks on the walls, floors and ceilings that allow the accumulation of dust and the breeding of vectors. Floors, drains and trenches should be easy to wash and rinse.

Materials and equipment contacting food surface should not impart color, odor or taste to the food brought in contact under normal condition, and should be durable, free of corrosion, decomposition, chipping and scratching. They should be non-absorbent, smooth and easily cleanable, except as specified a sink with at least 3 compartments and hot water and cold water supply shall be provided for manually washing, rinsing, and sanitizing equipment and utensils. Tables or drain boards shall be large enough to accommodate all soiled and cleaned items that may accumulate during operation hours. There shall be separate hand washing basins with hot and cold water taps, soap and hand drying facility conveniently located for use by consumers and food workers. Similarly there shall be separate flush toilets for food workers and customers. Toilet papers shall be available for cleaning all the time whether flush toilet or dry latrine is used. Septic tanks and pit latrines shall be located at a distance from the food preparing and serving area and solid waste including discarded food shall be stored in garbage container with tight lid for final disposal at the municipal refuse dump site or in a sanitary pit for composting [11].

Compared to the above requirements, among the establishments inspected only 290 (40.4\%) of them had three compartment sinks for washing utensils and equipment and the rest used single and double compartment sinks and large containers. About 144 (49.7\%) of them kept food contact surfaces in the kitchen in a clean condition. None of the establishments used mechanical dish washer. In about 358(49.7\%) of the establishments, food preparation, storage and serving areas were not kept in sanitary condition. In nearly $179(50 \%)$ of these establishments, insects and rodents were seen harboring the food preparation, storage and serving areas.

With regard to food waste and garbage disposal, the study revealed that about $372(51.9 \%)$ of the establishments inspected kept waste food in containers with fitting lid. About 237(33\%) of the establishments disposed wastes generated from their premises properly.

Regarding personal cleansing facility, the study showed that 540(75.2\%) had running pipe water, about 181 (33.6\%) were with hand washing facilities, and $167(31 \%)$ provided soap/detergents for hand washing. Latrine provision was seen in about 592(82.5\%) of the establishments with some of the latrines in a smelling and unsanitary condition for use including pit latrines. About $180(25 \%)$ were with adequate ventilation and $258(36 \%)$ with adequate lighting in the food preparation area. 


\subsubsection{Food Inspection Practices and Hygiene Compliance}

In about $549(76.5 \%)$ of the establishments, food safety inspection was being conducted by environmental health officers and health extension workers in the past. The result of the study showed that the majority 405 (73.8\%) of the establishments were not inspected regularly (with fixed time) by the health agent. The length of time after the last inspection was found to be more than six months in 438 $(79.8 \%)$ and less than six months in $111(20.2 \%)$ of the establishments. Regarding time spent during each inspection, the establishments reported that the inspector spent less than 30 minutes in 337 (61.4\%) localities, 30 to 60 minutes in 193 (35.1\%) establishments and more than 60 minutes in 19 (3.5\%) food serving entities. Of those 549 establishments inspected the majority $376(68.5 \%)$ didn't receive a written report or a copy of the completed inspection forms that show the results.

Only $24.2 \%$ of the establishments reported that the inspector has initiated action on the spot to correct minor violations identified before leaving the site. None of the establishments responded that the inspectors explain or teach about the corrective measures to be taken during each inspection. About $73 \%$ said that the inspector identifies imminent health hazard which may lead to suspension of permit unless compliance is made within a short time. $84 \%$ answered that the inspector has reviewed the menu or food list to check weather raw or undercooked foods are served or sold on routine basis. Only $23 \%$ of the food establishments' food workers /handlers were advised of their relevant legal obligations. Only $10 \%$ of the establishments ever received an advisory visit from inspectors on informal basis. None of the establishments had ever called the health agent in case of a problem. With regard to award schemes, none of the establishments were encouraged for their achievement in maintaining good food hygiene practices by awarding them certificates that rate their food safety performance.

\subsubsection{Barriers to Compliance}

Several barriers to compliance of existing food laws and regulations were identified. The major barriers were found to be inadequate knowledge and skill about food hygiene, lack of facilities and motivation, and limitation of resources. Around $80 \%$ of the respondents showed inadequate knowledge about what was legally required of them to do, particularly in relation to general food hygiene principles. A large percentage $(95.8 \%)$ of the respondents reported that they had not heard of hazard analysis in the past. A large percentage $(88.5 \%)$ of the respondents reported that they hadn't attended a food hygiene course in the past and were not aware of the current legislation and the type of food poisoning bacteria. About $96.8 \%$ of the establishments lacked trained staff (food handlers) in food safety. Only $1 \%$ of the food establishments sent staff for food hygiene course. None of these provided in-house training to their employees in food hygiene. None of them had a written food safety management system devised to monitor food safety in accordance with the principles of HACCP or safe food practice. Food preparers wore protective clothing in about 319 (44.4\%) of the establishments and those who did not wear was 399 $(55.6 \%)$. Most of the establishments interviewed demonstrated a lack of motivation, in particular in dealing with the training issues.

In about $84 \%$ of the food establishments money was perceived to be a barrier with respect to structural compliance and training requirements. 55\% of the respondents perceived time to be a barrier preventing the identification of regulations. Time was perceived to act as a barrier in around $73 \%$ of the establishments for temperature control, hazard analysis, training courses and structural issues. Time was seen perceived to act as a barrier in terms of documenting their hazard analysis, keeping temperature control records, or attending higher level food hygiene courses. The timing of the inspection often coincided with busy period in about $60 \%$ of the respondents, or when the proprietor wasn't there $67 \%$.

Only $2 \%$ of the establishments indicated that the inspector explores opportunities for formal event for the training of food handlers and other employees. Legal action had been taken on about $399(55.6 \%)$ for the non-compliance and the rest 319 (44.4\%) responded that legal action had never been taken against their establishments in the past. Specific legal measures were taken against 100 food establishments including submission of warning notes. Business was closed in 152 service places for non compliance and prosecution was made against 147 establishments. Only $22.8 \%$ of the respondents said that the inspector has explained why food hygiene and safety arrangements within the food business are important to prevent foodborne diseases and why food hygiene regulations and requirements should be applied in a proactive way to ensure food safety control.

\subsection{Transforming Research Results to Community Actions}

The results of the study showed the need for greater intervention to apply safe hygiene practices in the preparation of foods at home and catering establishments. It was observed that there was a knowledge gap in understanding existing food laws, regulations and standards by households and food service establishments. The need for a properly designed public health campaign to enhance food safety at all levels was realized. Consequently the report on food safety assessment at household level was published and distributed to community groups, health inspectors and responsible public health agents. This was followed by preparing manuals in local language on food hygiene, foodborne diseases, major cause of food spoilage, environmental sanitation and existing food laws and regulations. This was to be followed by organizing a training workshop aimed at 
creating awareness about food safety in the community and educate them on simple and practical sanitary measures to prevent foodborne diseases.

The World Health Organization is aware of the rising trend of foodborne diseases globally and as a result the theme of World Health Day on April 7, 2015 was " Food Safety: From Farm to Plate Make Food Safe". In commemoration of this day the Jimma University joined WHO by conducted a training workshop in which over 100 residents of Jimma town were drawn from different sectors including consumer's representatives, households, food service providers, government regulators, health inspectors, health extension workers and teachers. Key research findings from the two field surveys were presented to the participants followed by lectures in local language on food hygiene and foodborne diseases presented by Jimma University Environmental Health and Technology staff. WHO's 5 keys to safer food, environmental sanitation standards of food establishments including licensing and registration, risk based regulatory framework and enforcement strategies were among the subjects for discussion. The need to modernize existing food safety legislation by defining the role of government, food producers and consumers to ensure food safety from farm to table was elaborated.

At the end of the workshop participants were able to identify gaps and opportunities in implementing appropriate hygiene and sanitation practices at the household and food serving places to ensure the safety of consumers. The workshop provided the participants a platform to exchange knowledge and experiences about the increasing trend in foodborne diseases and the prevailing food safety risks. This enabled them to reach a consensus to improve the situation by applying affordable and practical basic sanitary measures to keep food safe with the help of environmental health officers and extension workers. At the end of the workshop participants came up with a long list of priority interventions to address the identified risk factors and formulated an action plan with implementation strategies. The report of the workshop was published and distributed to all participants and stakeholders to be used as a reference educational material to apply basic food hygiene and environmental sanitation practices and to monitor the implementation of their plan of action. There are all indications that food service providers and households are more concerned than ever before about the benefits of improving food safety in their community and are making greater efforts to reduce the burden of foodborne diseases in Jimma Town. The response of food managers in particular to this call was reported to be very encouraging.

\section{Discussion and Conclusions}

The studies demonstrate that food safety is a serious public health issue in Ethiopia as in other developing countries which has been overlooked in the past by governments and the public in general. As a result consumers are exposed to foodborne illnesses due to the unhygienic practices in the preparation of foods at home and catering establishments, and poor environmental health condition of the food premises. The traditional food inspection system does not provide the necessary tools and a clear mandate to the agencies concerned to prevent foodborne diseases. Our research identified varied knowledge, attitude and practice among households and food businesses on a number of areas including a lack of understanding on basic sanitary measures, limited awareness about food safety and a knowledge gap on existing food laws, regulations and standards. This raises the need for a properly designed aggressive public health campaign supported by risk based food inspection system as well as national information, education and communication programmes.

Enforcement objectives of food laws and standards seem to be driven by punitive measures than educational approach with minimal effort to help consumers and food service providers to understand and implement basic sanitary measures which will have better health results. Imposing unacceptably high penalty for violating sanitary rules and regulations did not bring positive results in improving the safety of food in the past. There is a need for a renewed emphasis on application of widely recognized science based inspection system, Hazard Analysis Critical Control Point (HACCP) to identify and prevent hazards from the initial stages of raw material production to the final stages of food preparation and consumption. Therefore the training of food inspectors in risk based approach (HACCP) and the provision of inspection tools and the necessary logistic support to improve their performance should be taken into consideration by the regulatory authority. The integration of food safety in the curriculum of primary and secondary education will also contribute to transforming hygiene and sanitation behavior of individuals that will impact the family and the community.

The study shows that food serving businesses breach regulations intentionally or unknowingly for different reasons. Most of the informal food businesses dispute or disregard the potential health impact of poor food hygiene practices and do not want to waste time and money on hazard control. Some food business owners and employees lack knowledge and training in food hygiene and since they do not have a clear perspective they want a health inspector or a third party to give them advice and a list of things they are expected to do to keep the food safe. A few catering establishments in the formal sector have a clear understanding of the hazards and health risks posed by poor food hygiene and believe that the regulations should be enforced effectively. These managers encourage their employees through staff training, regular medical examination and other incentives to take a lead in applying 
good hygiene practice of their food business. Under this circumstances the health inspectors are required to convince with evidence those who breach the regulations that their business is at risk unless they take positive action to comply with the basic food hygiene law. In view of the current disparity in compliance the managers and their employees having a problem should be given advice and training to understand the food hazards and the control measures and how compliance can be achieved. Managers and food workers should be encouraged to develop independent thinking and to understand that it is their duty to take proactive involvement in improving performance since inspectors will not be there all the time. Therefore food inspection needs frequent home visit, face to face explanation of associated risks, and voluntary compliance of regulations with a clear understanding of the compliance process.

The workshop was an eye opener to the participants who acknowledged that they have learnt a lot from the lectures given and from the experiences exchanged. They were committed to use the lessons learnt to change their approaches to dealing with food safety by preparing action plan and implementation strategies. They emphasized the need to train food service managers and workers on how to minimize food safety risks including direct face to face discussion in order to bring meaningful changes. Equally important was the licensing of food establishments and systematic inspection of premises where food is prepared and served. The modernizing of existing food safety legislation and code of practices and defining the role of the various agencies responsible for food safety was recognized as an issue of high priority. The licensing of catering establishments, the medical examination of food workers, the certification of food service providers, the provision of basic sanitary facilities including safe drinking water, clean toilets and adequate waste disposal facilities to reduce the risk of foodborne diseases were endorsed as essential ingredients of the food safety control system and agreed to be enforced at all levels. It was also recommended to improve the environmental sanitation of the open markets where perishable raw foods, meat, fish, milk, eggs, poultry, fruits and vegetables are bought for consumption at home and food establishments. There was also a consensus that food safety inspection should be extended to the primary producers at the farms, and the informal open markets.

The Government of Ethiopia has declared that it is in the process of updating and modernizing the country's food safety, animal and plant health system. This ongoing and evolving modernization process is in part attributed to the nation's fast-moving, export oriented economic growth, which has spurred a rising number of retail and whole sale food outlets, restaurants and food manufacturers in the new industrial parks. However Ethiopia's food safety regime is still in its early stages. At present food safety is economically driven to take advantage of international trade opportunities by increasing exports. On the other hand the health benefits of safe food by reducing mortality and morbidity from foodborne diseases in the country and the substantial cost for hospitalization and treatment of the preventable diseases has not been well recognized by the concerned authorities. Our study shows that a lot has to be done to fill the gap that exists in the health manpower (quality and quantity of food inspectors), tools, equipment and laboratory facilities for food examination, legal and regulatory framework and codes of practice, that make enforcement difficult. Many of the gaps should be gradually addressed by increasing public awareness of food safety through aggressive health education campaign and enforcing food safety and quality regulations effectively from farm to fork. The food markets, groceries, retail shops, the formal and informal food businesses need substantial structural and sanitary improvements to reduce the risk of contamination of raw and ready-to-eat foods by environmental hazards. All the studies carried out in other cities and towns of Ethiopia (Addis Ababa, Agaro, Bahir Dar, Mekelle, Zewai) have identified these urgent needs. This requires the active collaboration and coordination of the ministries of Health, Agriculture including Fisheries, Trade and Industry, Tourism, Ethiopian Standard Institution, National Food Authority, local and municipal governments and, Consumers Associations.

\section{The Way Forward}

The decentralization of the Ethiopian Food, Medicine, and Health Care Administration and Control Authority (FMHACA) which is the executive organ for food safety and quality administration and control is a step in the right direction to make the Authority focus on rendering efficient regulatory services. However the country's new direction being the expansion of agro-industrial parks the primary objective of modernizing the food safety and quality control system is to meet international sanitary and phyto-sanitary standards to fully benefit from regional and international food trade to boost the economy. Such effort should at the same time provide opportunity to enhance the safety of domestic food products by restricting the manufacturing, importing, storing and distributing for sale of any food item to the public without permit from the appropriate organ.

The restructuring of FMHACA should lead to the establishment of The Ethiopian Food Safety and Quality Control Authority with branch offices in all the regions which will be responsible for developing and implementing of policies that affect food safety, trade and public health, including capacity to implement relevant national and international food safety standards and regulations.

Management of food safety is a multi-sectoral affair in 
Ethiopia involving the ministries of Health, Agriculture, Fisheries, Trade/Industry the Standards Institution, local governments and municipalities. The FMHACA should establish sustainable coordination mechanism with well-defined responsibilities for each agency at Federal, Regional, Woreda and local level. Accordingly the Ministry of Health should play a leading role in the national food inspection services and take appropriate measures to improve the professional status of the food inspectors by providing them with the necessary tools to perform their duties. The Ministry should also assess the reliability and relevance of the inspection system and procedure used, as well as the training provided to the inspectors in relation to risk assessment of food safety issues and knowledge in food management tools such as Hazard Analysis Critical Control Points (HACCP). The Ministry of Health should ensure that food inspection services cover the entire country and not be limited to the formal urban and periurban areas and small towns in a manner that takes into account priorities in terms of risks to the consumers. Environmental health officers and health extension workers who play important role in the food inspection services should be motivated and provided with the necessary tools including training to perform their duties efficiently.

The Ministry of Agriculture regulates pesticides and other contaminants by conducting pesticide residue analysis in primary agricultural products as well as sets limits for heavy metals such as lead and microbiological contaminants on imported and domestically produced fruits. The Ministry also sets standard for veterinary drugs and other related compounds including the safety of imported plant products as authorized in the Plant Quarantine Regulation. The Guideline for Import and Export of Animal Genetic Material spells out the recommended procedures and requirement. Imports of livestock, meat, fish dairy products and genetic materials need health certificate from the country of origin and are subject to inspection. The import of plants and related articles must be accompanied by import permit and a phyto-sanitary certification from the country of origin. Paradoxically the inspection of primary products such as cereals, meat, poultry, fish, fruits and vegetables for residual pesticides, aflatoxin and other chemical, physical and microbial contaminants at the farm for local consumption is currently not in line with the food safety and quality assurance requirements. Therefore the Ministry should make efforts to ensure the safety of food at the source of production by engaging agricultural and health extension workers, assisted by veteran lan. Practices aimed at improving food safety at the farms also reduce post-harvest food losses increasing food availability and should therefore be promoted.

The Ethiopian Standards Agency develops the national food safety Standards some of which are mandatory while others are voluntary. Mandatory standards have the force of law and are enforced by laws and administrative regulations. Food products subject to specific compulsory requirements are fresh and canned fruits and vegetables, coffee, non-alcoholic beverages, edible oil seeds, food additives as well as prepackaged food. However the Agency is more engaged in the control of the standard of imported food than food produced for local consumption. As a result the safety and quality of locally produced food sold in the open markets, supermarkets and grocery stores could be of sub-standard since there is no inspection system for these markets. Hence the Agency should make efforts to improve the standard and quality of foods sold in the informal markets to enhance the safety of local food products in coordination with the Ministry of Agriculture and Ministry of Health.

The Ministry of Trade has the authority to control the quality of imports and exports and put restrictions as necessary when food items that do not comply with the required national or international standard enter or leave the country. It works closely with FMHACA, Ministry of Health and The Ethiopian Standard Agency to fulfill its mandate. The Ministry has the right to conduct random sampling and testing to certify that the food product meets the required standard. The World Trade Organization has placed a considerable obligation on both importing and exporting countries to strengthen their food safety system to comply with the agreement on the application of sanitary and phyto-sanitary measures. The development of modern national food safety system for Ethiopia is therefore a prerequisite to take part in the global food trade and forge membership to the World Trade Organization.

Foodborne diseases surveillance system is non-existence in Ethiopia due to lack of efficient food analysis capabilities at national and regional level. The only referral public health laboratory in the country is The Ethiopian Health and Nutrition Research Institute under the Federal Ministry of Health that has the competence to test for microbiological and chemical contaminants of food. Due to the limitation of the surveillance infrastructure there is no reliable data on the burden of foodborne diseases to convince policy makers about the public health importance of allocating funds to prevent foodborne diseases. However health statistics show that in Ethiopia on average a child experiences five to twelve diarrhea episodes a year and more than 250,000 children under the age of five years of age die annually as a result of diseases related to poor environmental sanitation and hygiene [4]. Moreover acute watery diarrhea continues to be a threat to the social and economic development of the country. Therefore the establishment of regional and sub-regional food testing laboratories and the expansion and consolidation of existing laboratories to include food testing to cover the entire country will strengthen the food inspection services and the epidemiological surveillance of foodborne diseases. In this regard the integration of the food testing laboratories, to water quality testing or the Antimicrobial Resistance 
(AMR) microbiology labs will substantially reduce the cost of infrastructure, equipment and laboratory technicians. The training of primary health care doctors in epidemiology to keep records of patients that have been treated for gastroenteritis, watery diarrhea could be part of foodborne diseases surveillance activity that could be extended to the Woreda health centre level.

The most effective intervention to reduce the burden of foodborne diseases is protecting food from contamination by pathogenic organisms, viruses, parasites, molds, rodents toxic chemicals, in the air, water and land. The application of basic sanitary measures in households, food establishments, open markets, supermarkets, food industries and agricultural farms have been recognized as major preventive strategy. A good example of effective hygiene intervention is hand washing with soap before and after contact with food which has been found to have a substantial impact in reducing the incidence of diarrhea among the poor. Public awareness, information, education and motivation to change hygiene behavior and comply with the food safety laws and regulations can be instituted by developing a national food safety advancement action plan with target and implementation strategies. National efforts to promote behavioral changes with respect to hygiene and sanitation have been going on in Ethiopia since 2006 which showed some improvement in both rural and urban areas. The health extension workers supported by community volunteers and health development army were instrumental in bringing the accelerated change. Equally important for the success of the initiative was the strong political commitment which was complemented by signing a Memorandum of Understanding by the Ministry of Health, Water Resources, Education and Finance, to harmonize different approaches and provide a clear road map for resource mobilization, coordination and implementation of the programme.

Based on the experience and lessons learnt from the ongoing Community Led Total Sanitation (CLTS) programme which is being implemented under the leadership of the Ministry of Health and regional health bureau, the Ministry of Health is well placed to initiate a national awareness campaign in consultation with the ministries of Agriculture, Trade, Ethiopian Standard Institute, FMHACA on the dangers of the public exposure to unsafe foods due to inadequate control of food hazards and deteriorating sanitary condition of food serving establishments. The consultation should lead to the establishment of National Food Safety Control Task Force under the Federal Ministry of Health and different working groups representing the ministries, agencies and other organizations responsible for food safety. Under such arrangement the current National Food Safety Control System should be reviewed including the various laws and regulations that have been enacted over the years to regulate and enhance food safety. The implementation of policies to ensure compliance and the development of infrastructure and institutional capacities including the coordination and surveillance mechanisms should be assessed. It should be recognized that assuring food safety along the entire food chain can be made possible by providing the different stake holders, individuals, families, communities, farmers, food producers, food traders and consumers, the information and education necessary to minimize food safety related risks. Therefore concerted efforts should be made to enhance effective health promotion and training programmes as integral part of National Food Safety Control System in order to achieve sustainable public health and economic development in Ethiopia.

\section{Recommendations}

\subsection{Legislation, Policy and Strategies}

1. The new Food Safety Authority which has primary responsibility for food safety should bring the fragmented national food control system under one management by establishing a sustainable co-ordination mechanism with well-defined responsibilities for each agency and delegate authorities to Regional, Woreda, Municipal and Kebele local governments to institute effective food safety policies and strategies to reduce the burden of foodborne diseases, and enhance economic growth and public health development.

2. Review and update existing food safety laws and regulations in an effort to create modern food law that ensures the production, distribution and sell of safe and wholesome food for domestic supply and export purpose.

3. Formulate national food safety policy and strategies to provide a basis for the establishment of the food safety objectives, requirements, and guidance that can be applied to the various sectors of the food continuum including primary production, processing, storage, transportation, marketing, preparation and consumption. The policy should aim at providing confidence to consumers and ensure public health.

4. Establish procedures to ensure that regulations, policies and directives are developed and enforced in a consistent, transparent and interactive participatory manner, and that the associated processes are generally open to the public in a manner that the objectivity and integrity of all food safety decisions are made clear.

5. Identify stakeholders who have vested interest in food safety including institutions, government ministries, non-government organizations, primary producers, industries, processors, food service providers, supermarkets and small food business owners and consumers, and ensure their participation in all 
aspects of the development and implementation of the policy.

6. Establish strong and viable inter-ministerial, inter-agency, and multi-sect oral working committees to be coordinated by The Food Authority, to articulate a plan of action to translate the policy into implementation programmes.

7. Stimulate political will by creating awareness based on the evidence of situation analysis studies including records of mortality and morbidity from foodborne diseases, food adulteration reported cases, as well as existing and emerging trends influencing food safety at each stage of the food chain. Political commitment should stimulate the allocation of adequate resources by the government by prioritizing the issues and problems to be addressed.

\subsection{Improving the Current Food Inspection System}

8. Health inspectors and Extension workers in charge of inspection of food premises should be flexible to achieve a better cooperation by using a wide array of informal techniques such as education, persuasion, negotiations to remedy existing problems. Prosecution should be regarded as a last resort unless there is lack of cooperation and positive response by the violators. Taking immediate legal action against offenders may create complications since most Food Safety Acts do not describe offensive acts in detail unless accompanied by clear regulations. Thus food inspectors should be encouraged to practice educational approach rather than the traditional command and control food inspection method.

9. The current food inspection system is not effective due to low concern in national, regional and local government policies resulting in lack of adequate resources in terms of priorities for funding, manpower training, provision of laboratory support for food analysis, and lack of logistics including transport and inspection tools. Local governments lack operational budget and they only pay salaries making it difficult for the food inspectors to perform their duties effectively. Since scare government resources are allocated to priority needs, there is a need for strong advocacy to provide adequate financial support for food inspection to make sure that safe and wholesome food is supplied to consumers.

10. Food inspectors should be empowered to play a vital role in consumers' protection even though the producer, manufacturer and the food service operators have equal responsibility. Food safety risks arising from sanitation violation that lead to food contamination by hazardous substances that may cause disease outbreak, should be reported to the appropriate regulatory agency to exercise a direct influence over food safety risk management.
11. Food inspectors should be trained in risk analysis process which provides a structured systematic approach to identifying, assessing, and managing health risks and emphasizes stakeholders consultation and communication. This is compatible and consistent with approaches developed at the international level by the Codex Alimentarious Commission and with the guidance on food safety risk analysis provided by $\mathrm{FAO} / \mathrm{WHO}$.

12. With major institutional changes for food safety that led to the establishment of the Food Safety Authority, the inspection of major agro industries in the Agro Industrial Parks, large food manufacturing and processing enterprises, commercial agriculture, poultry and dairy farms, fisheries, abattoirs, supermarkets, large hotels, restaurants and mass catering institutions should apply risk based regulatory system for which specialized knowledge is required by the food inspectors. The food inspectors assigned to these high profile food enterprises should therefore be trained in the Hazard Analysis Critical Control Points (HACCP) principles while small and medium businesses continue to be inspected by command and control system with a wide array of informal techniques such as education, persuasion and negotiations.

\subsection{Hygiene Compliance of Food Establishments}

13. Strengthen the capacity of local authorities to implement effective food inspection services on regular basis by playing a role as educators rather than enforcers and by providing them with the enabling policy, legislation, strategies, code of food hygiene practices and resources.

14. Extend the food inspection service to the informal sector open markets, street food vendors and to the rural areas where primary products are collected from thousands of small holdings ultimately reaching the urban population through local traders in the supply chain for direct consumption. Several studies confirm that small food businesses and street food vending pose significant health risk to consumers due to lack of knowledge of street vendors on basic food hygiene and the exposure of street foods to environmental hazards (chemical, physical, biological).

15. In view of the deplorable sanitary and environmental condition of food establishments particularly small hotels, restaurants, and open food markets in the urban areas, the regulatory authority should pay due attention to improve the condition by ensuring the availability of safe water, clean toilet facilities with hand washing basins and appropriate solid and liquid waste collection and disposal system. Particular attention should be given to maintain a good repair of the kitchen where there is greater risk of cross 
contamination and temperature abuse due to improper washing of utensils and unsafe storage of perishable and ready to eat food stuff including contact with food handlers who do not practice good personal hygiene.

16. Develop or use existing educational materials prepared for food workers and managers by WHO, FAO and others to engage them in food hygiene and restaurant procedure training in order to fully understand the factors that impact food safety in the food service establishments. At the same time motivate the employees who have acquired basic knowledge of safe food preparation and handling by providing them the necessary support to develop and implement activities that would contribute to effective food safety management.

17. Encourage food business managers to maintain acceptable sanitary and hygiene standard of their food premises by providing them health information and familiarizing them with the existing regulations and code of practices during regular inspection. Managers should receive a copy of the inspection report and be advised on important issues such as the requirement for medical examination of the food handlers, timely renewal of their licenses, use of proper equipment and utensils and, allocating time and resources for training of staff.

\subsection{Open Markets and Street Food Vending}

18. Empower open market food traders and street vendors to become an integral part of the urban and rural life by providing them permanent built up structure at convenient locations with facilities to store and display food safely without risk to contamination by pathogenic organisms, dust, chemicals and extreme heat. The construction of municipal owned rental modern food kiosks or stalls to house the street vendors and open market food traders will add to the safety and well-being of consumers. The current practice of food vending in the urban areas gives a bad image to the municipal health authorities due to exposure of perishable and ready to eat food stuff to environmental hazards.

19. Register street food vendors and organize them to form associations or unions or cooperatives to get approval of the local authorities and enable them to have operational guidance, get loans from banks to expand their business and invest in infrastructure development. Since vendors prepare food at home and on site there is a need to educate them on food hygiene and to make them aware of the importance of taking regular medical examination. Food samples should also be taken for bacteriological examination by the health inspectors on regular basis as preventive control.
20. Make special provision on the sanitary requirement for the storage and sell of perishable and ready-to-eat foods such as meat in butcheries shop, milk and milk products, fish, eggs, chicken fresh fruits and vegetables, bread and juices to ensure that these food items are kept under temperature that retard the growth of pathogenic organisms. Provide manuals on the hygiene requirements of these food stuff.

\subsection{Foodborne Disease Surveillance, Education and Communication}

21. Increase the capabilities for microbiological and chemical analysis of food to cover all regions by establishing more laboratories to implement foodborne disease surveillance programme. In this regard consideration should be made to integrate foodborne disease surveillance system to existing water quality surveillance or Antimicrobial Resistance (AMR) microbiology labs to reduce the cost of infrastructure, equipment and laboratory technicians.

22. Monitor trends in foodborne diseases caused by the key pathogenic bacteria Salmonella, Campylobacter, Listeria, E.coli and Mycobacterium through laboratory confirmed cases of illness when someone suffering from foodborne disease symptoms is sent to a laboratory by a health care provider to give stool sample. Although we can't be sure exactly how many cases of food poisoning there are, we can make reasonable estimate $\mathrm{s}$ of trends and tell whether the number of cases is going up or down. Another way of estimating trend is using telephone survey to determine the total amount of infectious gastroenteritis in a typical year or collecting epidemiological data from hospitals and other health facilities on the number of cases, hospitalizations and deaths due to foodborne gastroenteritis. Although these confirmed cases only represent a fraction of the total, the system doe provide a consistent indication of trends in some of the key foodborne diseases caused by the pathogens.

23. Create national awareness about the health and economic threats of the rapidly increasing foodborne diseases due to the poor sanitary condition of the environment where our food is produced, marketed, prepared and consumed and due to unhygienic practice of food handling in the domestic and food serving establishments. An even greater challenge to food safety will come as new pathogens are identified from climate change, changes in ecological system, production methods, processes and habits. Antimicrobial resistance is the most alarming threat resulting in deaths.

24. Initiate and implement national educational campaign to keep food safe from farm to table by mobilizing 
stake holders and organizing community meetings, training workshops, useof extensive public media, radio programmes, public speeches, and distributing posters, fliers, and manuals on basic hygiene practices.

25. Ensure the application of best practices, standards, regulations and scientific approaches to risk management such as "HACCP" by large food processing and manufacturing industries to avoid the risk of food recalls by national and international trade partners.

26. Promote proactive engagement of consumers by organizing them in association at different levels, to be involved in food alert, adulteration and other fraudulent activities. Consumers should be educated how to keep food safe to prevent foodborne diseases so that they become part of the solution and demand a safe food supply.

27. Raise consumers' confidence by informing and educating them on safe food preparation and handling in the domestic environment. Most consumers are aware of major food contamination sources and are in favor of implementing measures that reduce risk of foodborne illnesses but they lack adequate knowledge and therefore have to be informed and technically guided. Public consciousness of food adulteration and contamination will contribute to the early detection of fraud and hazard before the damage occurs.

28. Integrate food hygiene in the curriculum of primary and secondary education so that good hygiene behavior becomes part of the way of life of the young generation contributing to the health and economic wellbeing of individuals, families and communities.

29. Review the Environmental Health undergraduate degree programme to ensure food safety is adequately covered to address the country's need including risk assessment and management, food processing critical control points, food packaging, labeling and food defense.

30. In view of the scientific and technological development of food processing and the growing trend of agro industrial parks in the country, establish a department of Food Science and Technology to train food technologists and scientists for innovation and research in safe food production.

\section{Acknowledgements}

We are very grateful to all food safety study and workshop participants for their valuable supports and cooperations.

\section{REFERENCES}

[1] Daniel Teffera. Ethiopia: Inflationary Growth and Food Deficiency (2014).

[2] James A Flint, Yvonne T.Van, Dacy N Hoven. Estimating the Burden of Acute Gastroenteritis, Foodborne Disease, and Pathogens Commonly Transmitted by Food: An International Review. Food Safety, CID 41: 699, 2005.

[3] World Health Organization (WHO). Estimates of the Global Burden of Foodborne Diseases (2015).

[4] Ethiopian Weekly Epidemiological Bulletin. Vol 4, No. 39, Week 39/2018.

[5] Henok Fente, Salem Solomon, Eskinder Frew. Ethiopia Declares Another Diarrhea Outbreak. VOA 2017.

[6] Xan Rice. Fatal Outbreak not a Cholera Epidemic Insists Ethiopia. The Guardian (2007).

[7] Zelalem Ayana, Moti Yohannis, and Zelalem Abera. Foodborne Baterial Diseases in Ethiopia. Academic Journal of Nutrition, 4(1): 62-76, 2015.

[8] Ethiopian Health and Nutrition Institute. Guideline on Cholera Outbreak Management (2011).

[9] Laura R Green and Carol Selman. Food Workers' and Managers' Safe Food Preparation Practices: a Qualitative Study. Food Protection Trends, 25(12): 981-990, 2005.

[10] Bryan FL. Risks of Practices, Procedures, and Processes that Lead to Outbreak of Foodborne Diseases (1988).

[11] Teka GE. Food Hygiene. Principles and Methods of Foodborne Diseases Control with Special Reference to Ethiopia, 1997, Addis Ababa, Ethiopia.

[12] Addis Z., K.Nigatu, S. Zufan, A.Haile, Y. Alehegne and K. Tesfu. Prevalence and Antimicrobial Resistance of Salmonella Isolated from Lactating Cows and Incontact humans in Dairy Farms of Addis Ababa (2011).

[13] Assefa M, T.Akafete and N.Haileleul. The Prevalence and Public Health Importance of Salmonella from Chicken Table Eggs. Ministry of Agriculture, Kombolcha Agricultural Bureau. American-Eurasian J. Agric. \& Environ. Sci., 11 (4): 512-518, 2011.

[14] Sefinew, A. and M. Bayleyegn. Prevalence and Antimicrobial Resistance Profiles of Salmonella Enterica Serovars Isolated from Slaughtered Cattle in Bahir Dar, Ethiopia (2012).

[15] Solomon, E.B and D.G. Hoover. Campylobacter Jejuni a Bacterial Paradox, J. food Safety, 19:121-136, 1999.

[16] Lemma, D. and A. Daniel. Prevalence and Antimicrobial Susceptibility Profiles of Thermotolerant Campylobacter Strains in Retail Raw Meat Products in Ethiopia. Ethiop. J. Health Dev., 22(2): 2008.

[17] Tesfaye, K., G. Solomon and A. Daniel. The Prevalence of Thermotolerant Campylobacter Species in Food Animals in Jimma Zone, South West Ethiopia. Ethiop. J. Health Dev, 19(3):225-229, 2005. 
[18] Firehiwot A. Prevalence and Antimicrobial Profile of Listeria Monocytogens in Retail Meat, Poultry and Dairy Products in Addis and its Surrounding Town, Ethiopia. MSc thesis, Addis Ababa University, Addis Ababa, Ethiopia; 2007.

[19] Legesse Garedew, Ayele Tadesse, Tigist Biru, Seleshi Nigatu, Elias Kebede, Mebrat Eijo, Abrham Fikre and Tamiru Birhanu. Prevalence and Antimicrobial Susceptibility Profile of Listeria Species from Ready to Eat Foods of Animal Origin in Gondar town, Ethiopia. BMC Microbiology, 15:100, 2015.

[20] Tesgne, M. and M. Ashenafi. Microbial Load and Incidence of Salmonella Species in "Kitfo", a Traditional Ethiopian Spiced, Minced Meat Dish. Ethiop.J.Health Dev., 12(2):135-140, 1998.

[21] Asrat Meleke, Andualem Henok, Worku Tefera, Tafesse Lamaro. 2015. Asessment of the Sanitary Conditions of Catering Establishments and Food Safety Knowledge and Practices of Food Handlers in Addis Ababa University Students' Cafeteria. Science Journal of Public Health, 3(5): 733-743, 2015.

[22] Kinfe Zeru, Abera Kumie. Sanitary conditions of food establishhments in Tigray, North Ethiopia. Ethuiop.J.Health Dev., 21(1): 1-1 08, 2008.

[23] Teklemarium S, Roma B, Sorsa S, Worku S, and Erosie L. Assessment of sanitary and hygienic status of catering establishments of Awassa Town. Ethiop. J. Health Dev., 14(1):91-98, 2000.

[24] Andargie G, Kassu A, Moges F, Tiruneh M, Huruy K. Prevalence of bacteria and intestinal parasites among food-handlers in Gondar town, northwest Ethiopia. J Health Popul Nutr.;26(4):451, 2008.

[25] Fessehaye A, Alemshet Y, Wondwossen B, Zewdineh S.M, Kenate W. Investigation of dysentery outbreak and its causes, Jimma city, Southwest Ethiopia. Ethiop. J. Health Sci., 19(3): 147-154, 2009.

[26] Abera, B., Biadegelgen, F. and Bezabih, B. Prevalence of Salmonella typhi and intestinal parasites among foodhandlers in Bahir Dar Town Northwest Ethiopia. Ethiop. J. Health Dev., 24 (1): 46-50, 2010.

[27] Okeke Ingeld and K.P Klugman. Antimicrobial Resistance in Developing Countries Part II. Strategies for Containment (2005).

[28] The Ethiopian Public Health Institute. The Surveillance of Antimicrobial Resistance Using Public Hea;th laboratory-Based Sentinel Sites in Ethiopia (2016-2020).

[29] World Bank. World Development Indicator (2014).

[30] Belayhun Kibret, Alemayehu Chala and Alemayehu Toma. Knowledge, Attitude and Practice of Farmers towards Aflatoxin in Cereal Crops in Wolaita Zone, Southern Ethiopia. EC Nutrition; 14(3): 247-254, 2019.

[31] World Health Organization. Advancing Food Safety Initiatives. WHO 63.3 (2010).

[32] Chander Pal,Thakur, Rakesh Mehra, Chahat Narula, Swati Mahaparta and Tapan JyotiKalita. Food Safety and Hygiene Practices Among Street Food Vendors in Delhi, India. International Journal of Current Research, 5(11):
$3531-3534,2013$.

[33] Firdu Zawide. Strengthening the Role of Street Food Vendors to Reduce the Burden of Foodborne Diseases in Developing Countries. Epidemiology, 20(6): 109-110, 2009.

[34] Wondwossen Birke, Abebe Gebremariam and Firdu Zawide. Investigation of Food Safety and Handling Practices of Households in Jimma Town, Southwestern Ethiopia. Epidemiology, 22(1): Ps 265, 2011.

[35] Clare T. Romanik. An Urban-Rural focus on Food Markets in Africa. The Urban Institute (2008).

[36] Kibret M, Abera B. Sanitary condition of Food Service Establishments and Food Safety Knowledge and practices of Food Handlers in Bahirdar town Amhara. Ethiop. J. Health Dev., 22(1): 27-35, 2012.

[37] Zemichael Gizaw. Food safety knowledge, attitude and associated factors of food handlers working in substandard food establishments in Gondar town, Northwest Ethiopia. International Journal of Medical and Health Sciences Research, 1(4): 37-49, 2014.

[38] Zeru, K., Kumie, A. Sanitary conditions of food establishments in Mekelle town, Tigray, North Ethiopia. Ethiop. J. Health Dev., 2(1):1-9, 2008.

[39] Biruk G, Wondwossen B. Hygienic Setting of Catering Establishments in Agaro Town, Southwestern Ethiopia. JOJ Pub Health, 3(3): 555-611, 2018.

[40] Mariam, S.T., Roma, B., Sorsa, S., Worku, S. \& Erosie, L. Assessment of sanitary and hygienic status of catering establishments of Awassa Town. Ethiop. J. Health Dev., 14, 91-98, 2000.

[41] Kumie A, Genete K, Worku H, Kebede E, Ayele F, et al. The sanitary condition of public catering establishments in the district of Zeway. Ethiop. J. Health Dev., 14(1): 91-98, 2002.

[42] Federal Ministry of Health. Proclamation No. 661/2009. A Proclamation to Provide for Food, Medicine and Health Care Administration and Control. 